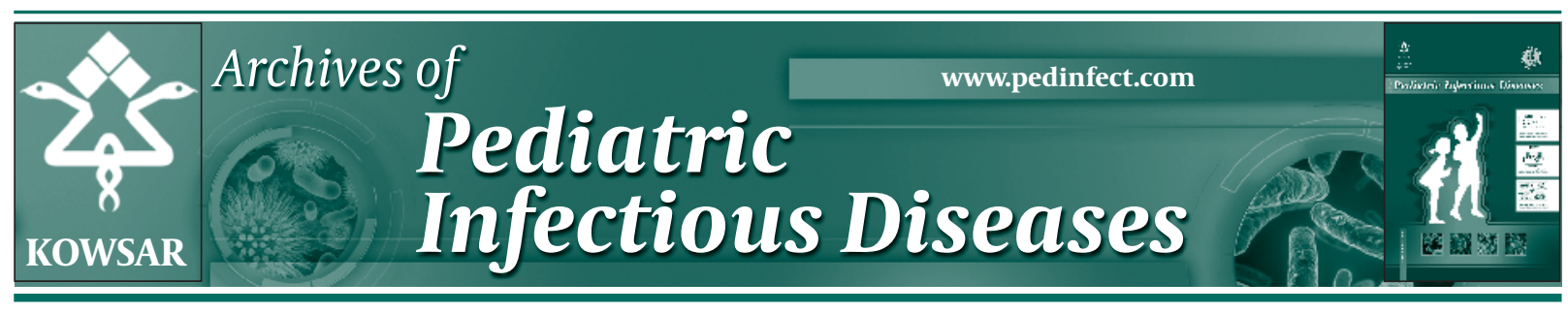

\title{
Detection of Noroviruses Isolated From Children With Acute Gastroenteritis by Rt-PCR in Iran
}

\author{
Sara Rahmati Roodsari ${ }^{1}$, Fatemeh Bitajian ${ }^{2}$, Latif Gachkar ${ }^{1}$, Farzaneh Jadali ${ }^{3}$, Saadat Ada- \\ bian $^{3}$, Raheleh Sadat Sajadi Nia ${ }^{4}$, Saeid Maham ${ }^{3, *}$ \\ ${ }^{1}$ Infectious Diseases and Tropical Medicine Research Center, Shahid Beheshti University of Medical Sciences, Tehran, IR Iran \\ ${ }^{2}$ Semiology Departement, Shahid Beheshti University of Medical Sciences, Tehran, IR Iran \\ ${ }^{3}$ Pediatric Infections Research Center, Shahid Beheshti University of Medical Sciences, Tehran, IR Iran \\ ${ }^{4}$ Medical University, Shahid Beheshti University of Medical Sciences, Tehran, IR Iran \\ * Corresponding author: Saeid Maham, Pediatric Infections Research Center, Shahid Beheshti University of Medical Sciences, Tehran, IR Iran. Tel.: +98- \\ 2122907004, Fax:+98-2122907004, E-mail:mahamsm@yahoo.com
}

\begin{abstract}
A B S T R A C T
Background: Noroviruses are one of the major viral pathogens responsible for gastroenteritis. Outbreaks of diarrhea due to Norovirus have been reported frequently. This study is performed to determine the prevalence of Norovirus in fecal specimens of children with gastroenteritis. Many viruses can cause gastroenteritis, including Rotaviruses; Adenoviruses types 40 and 41 ; Sapoviruses; and Noroviruses. Current techniques used for detection of Noroviruses in stool samples include multi-step viral RNA extraction and purification followed by reverse transcriptase-polymerase chain reaction (Rt-PCR).

Objectives: The purpose of this study is to detect Norovirus in stool samples by Rt-PCR in 5 different centers in Iran.

Patients and Methods: In this study, 2,170 stool samples were collected from children less than five years old from five different cities, all of whom had acute gastroenteritis. Detection of Noroviruses was performed through Rt-PCR. The mean age of the studied population was 48 months. Fecal specimens were collected within 24 hours of admission. The specimens were frozen, sent to the laboratory, and then stored at $-70^{\circ} \mathrm{C}$ until being tested for Norovirus.

Results: Rt-PCR was performed for 2,170 stool samples containing 90 (4.14\%) Norovirus positive (0.97\% Tehran, 0.64\% Tabriz, 0.18\% Mashhad, 1.57\% Shiraz, 0.78\% Bandar Abbas). The RT-PCR was validated with published primers for Norovirus (JV12/JV13). In both retrospective and prospective settings, the Rt-PCR was equally sensitive (95\%) and specific (95\%) in detecting Norovirus.

Conclusions: Noroviruses, which are important human pathogens, may cause epidemic acute viral gastroenteritis which in turn can be easily detected by molecular methods.
\end{abstract}

Keywords: Gastroenteritis; Child; Norovirus; Reverse Transcriptase Polymerase Chain Reaction

Copyright () 2013, Pediatric Infections Research Center

Article type: Research Article; Received: 08 Aug 2012, Revised: 14 Dec 2012, Accepted: 29 Dec 2012; DOI: 10.5812/pedinfect.7619

-Implication for health policy/practice/research/medical education:

This is a unique study which uses RT-PCR to detect Norovirus in the stool samples of children suffering from acute viral gastroenteritis.

-Please cite this paper as:

Roodsari SR, Bitajian F, Gachkar L, Jadali F, Adabian S, Sajadi Nia RS, et al. Detection of Noroviruses Isolated From Children With Acute Gastroenteritis by Rt-PCR in Iran. Arch Pediatr Infect Dis.2013;1(2): 57-60. DOI: 10.5812/pedinfect.7916

Copyright (C) 2013, Pediatric Infections Research Center

This is an Open Access article distributed under the terms of the Creative Commons Attribution License (http://creativecommons.org/licenses/by/3.0), which permits unrestricted use, distribution, and reproduction in any medium, provided the original work is properly cited. 


\section{Background}

Acute gastroenteritis is an important cause of childhood morbidity and mortality, especially in children under 5 years old. Recently, it has been estimated that in developing countries, there are 450 million cases of diarrhea in children less than 5 years old annually and that $1-4 \%$ of them may die consequently. According to centers for disease control and prevention reports, Norovirus causes 23 million cases of acute gastroenteritis worldwide a year in all age groups (1). Norovirus can cause diarrhea in both adults and children (2). Noroviruses are most frequently recognized as a cause of gastrointestinal inflammation and causes more than $50 \%$ of all food borne disease in the US (3).

Among the viral infectious agents of acute gastroenteritis, Rotavirus, human Calicivirus, Astrovirus, and Adenovirus have been characterized $(4,5)$. The norwalk-like and sapporo-like viruses are recently renamed Norovirus and Sapoviruses, respectively. Norovirus is the one of the important triggers of febrile seizures (6). They are further divided into genogroups I and II, and which are responsible for approximately 179 million cases of acute gastroenteritis that occurs annually in the US (7). There are different methods to detect Norovirus such as ELISA (8), Real-Time (9), Rt-PCR (10), and cell culture (11). According to the varied etiology of Norovirus, they can be diagnosed by variety of diagnostic methods. In a study in Japan, the detection method of ELISA-kit is compared with RT-PCR . The ELISA method had a sensitivity of $76.3 \%$ and specificity of $94.9 \%$. However because of the kit sensitivity to most Norovirus genotypes, it needs to be improved (8). In addition, according to a study on children under 12 years old with gastroenteritis during a 4 year period in Tunisia, it was shown that $64.8 \%$ were affected by Norovirus gastroenteritis (11).

\section{Objectives}

Considering the comparison of Norovirus diagnostic methods in different studies, we studied the prevalence of Norovirus which causes gastroenteritis in children under 5 years old suffering from diarrhea in 5 different cities of Iran by Rt-PCR in order to detect the number of positive samples.

\section{Patients and Methods}

In this study, 2170 samples of children with acute gastroenteritis, who were admitted to the pediatric hospitals in 5 cities of Iran (Tehran, Mashhad, Tabriz, Shiraz, Bandar Abbas) were collected. Written informed consent was obtained from all patients.

Fecal specimens were collected within 24 hours of admission. The specimens were frozen, sent to the laboratory, and subsequently stored at $-70^{\circ} \mathrm{C}$ until Norovirus testing. Viral RNA was extracted from 30\% stool suspensions in physiologic serum, then centrifuged at $6000 \mathrm{rpm}$ for 20 minutes and filtered by $0.2 \mu \mathrm{m}$ filter. Then $140 \mu \mathrm{L}$ of the filtered samples was transferred to micro tubes and extracted by QIAamp viral RNA extraction mini kit (Qiagen, Hilden, Germany) following the manufacturer's instructions. The extracted samples were then stored at $-20^{\circ} \mathrm{C}$ for a short time and further studied using Rt-PCR.

The cDNA synthesis was carried out using Rt-premix kit (Bioneer, U.S.A). The PCR products were analyzed by electrophoresis on a $1 \%$ agarose gel and visualized with UV light. TBE buffer was used as the electrophoresis gel (12). The PCR products obtained using the primer set JV12/ JV13 was $326 \mathrm{bp}$. The primer pair sequences used in the study has been shown in Table 1 .

Table 1. The Primer Pair Sequences Used in This Study

\begin{tabular}{l}
\hline Primer Gene Location Polarity Sequence (5'-3') \\
\hline JV 12 RdRp 4277-4297 + AATACCACTATGAT GCAGATTA \\
JV 13 RdRp 4583-4603 - T TCATCATCACCATAGAAAGAG \\
\hline Abbreviation: RdRp, RNA-dependent RNA polymerase
\end{tabular}

\section{Results}

Detection of Norovirus in 2,170 stool samples was done using Rt-PCR which was authenticated with approved primers for Norovirus (JV12/JV13). The prevalence of Norovirus in 5 large cities of Iran was reported to be $4.14 \%$. There was no significant relationship between the patients age and their Norovirus-caused gastroenteritis ( $\mathrm{P}$ value $<0.05)$. The prevalence of Norovirus in different cities is studied and is shown in Table 2 . Gel electrophoresis results are shown in Figure 1.

\begin{tabular}{lll}
\hline \multicolumn{3}{l}{ Table 2. Prevalence of Norovirus in the Different Cities of Iran } \\
\hline City & Samples Positive & No. (\%) \\
\hline Tehran & 570 & $21(0.97)$ \\
Tabriz & 360 & $14(0.64)$ \\
Mashad & 240 & $4(0.18)$ \\
Shiraz & 690 & $34(1.50)$ \\
Bandarabbas & 310 & $17(0.78)$ \\
Total & 2170 & $90(4.14)$ \\
\hline
\end{tabular}

\section{Discussion}

Noroviruses are one of the most important causes of acute non-bacterial gastroenteritis in children (1). This virus can be spread easily; however, there have been no reports of Norovirus prevalence in Iran during the last two decadesIn this study, Norovirus was responsible for $4.14 \%$ of all acute gastroenteritises and the prevalence rate varied in the 5 different cities. In another study in Iran by Romani et al. in which 4 of 93 (4.5\%) samples 
were positive for Norovirus, 67 samples (61\%) had been collected from inpatients and 26 (39\%) from outpatients, all the positive samples belonged to the outpatients (13).

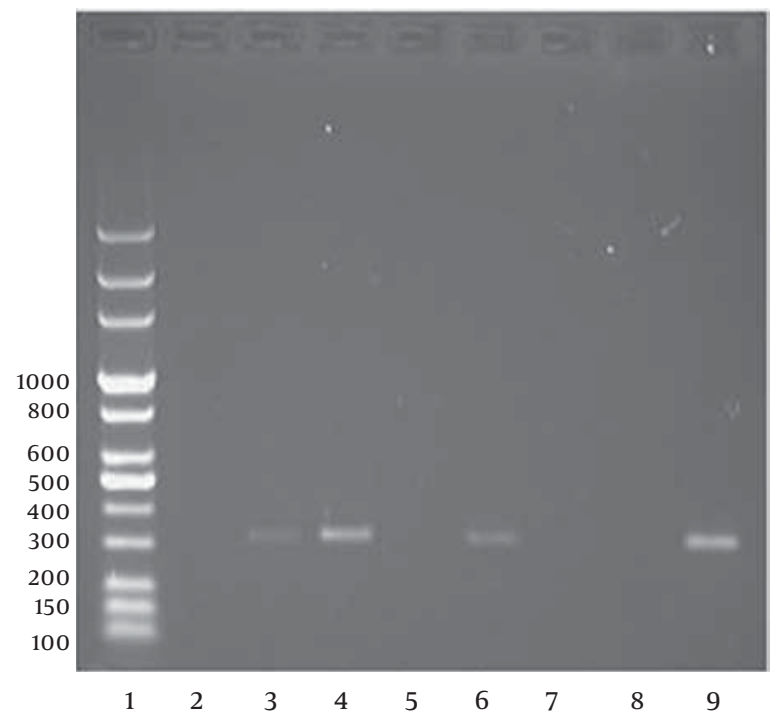

Figure 1. PCR Products on Gel Electrophoresis (326 bp)

In this study water resources for the patients were surveyed but no relationship between water and Norovirus infection was established. In countries with different dietary patterns, these statistics pattern may have some modifications. Norovirus outbreaks are reported to be $17.9 \%$ in Switzerland (14), $12 \%$ in Nicaragua (15), $21.9 \%$ in Taiwan (16), 9.9\% in Pakistan (17), 11.9\% in India (18), 48.4\% in Italy (19), and $12 \%$ in Brazil (20). This virus causes about $40 \%$ to $50 \%$ of food-related diseases in the US (21). The high prevalence of gastroenteritis caused by Norovirus in these countries can be due to various factors different from the middle east. For example, the consumption of raw marine products such as oysters is one of the main causes of Norovirus spread in developed countries (22); however, this dietary pattern is rare in middle eastern countries (including Iran)(13). Therefore, the prevalence of Norovirus in these countries is less. Norovirus gastroenteritis is seen in all age groups and therefore there are not any age limitations for contracting of the virus (12). Although the risk of Norovirus gastroenteritis is all year-round, nevertheless the peak of Norovirus infection is in cold seasons (23) therefore this disease is frequently referred to as cold season diarrhea (24). Since Norovirus is an RNA virus, RNA instability in high temperatures can cause more outbreaks in the second half of the year. In this study, the relation between geographic distribution and Norovirus infection was also considered.

It was shown that patients referred to Shiraz hospital had a higher percentage of Norovirus infection and which would indicate a need to do a survey of Norovirus outbreak in this area.
To sum up, Norovirus should be considered as one of the prevalent causes of acute gastroenteritis in children less than 5 years of age in Iran as well as many other countries, however comprehensive research is needed to estimate the exact number of infected children using accurate molecular methods.

\section{Acknowledgements}

This study was supported by the Infectious Disease and Tropical Medicine Research Center and Pediatric Infectious Research Center (PIRC), Mofid Children Hospital, Shahid Beheshti University of Medical Sciences, Tehran, Iran.

\section{Authors' Contribution}

None declared.

\section{Financial Disclosure}

None declared.

\section{Funding/Support}

None declared.

\section{References}

1. Giordano MO, Ferreyra LJ, Isa MB, Martinez LC, Yudowsky SI, Nates SV. The epidemiology of acute viral gastroenteritis in hospitalized children in Cordoba City, Argentina: an insight of disease burden. Rev Inst Med Trop Sao Paulo. 2001;43(4):193-7.

2. Nordgren J. Norovirus Epidemiology: Prevalence, transmission, and determinants of disease susceptibility.2009.

3. Widdowson MA, Sulka A, Bulens SN, Beard RS, Chaves SS, Hammond R, et al. Norovirus and foodborne disease, United States, 1991-2000. Emerg Infect Dis. 2005;11(1):95-102.

4. Basu G, Rossouw J, Sebunya TK, Gashe BA, de Beer M, Dewar JB, et al. Prevalence of rotavirus, adenovirus and astrovirus infection in young children with gastroenteritis in Gaborone, Botswana. East Afr Med J. 2003;80(12):652-5.

5. Minosse C, Zaniratti MS, Calcaterra S, Carletti F, Muscillo M, Pisciotta M, et al. Application of a molecular panel to demonstrate enterotropic virus shedding by healthy and human immunodeficiency virus-infected patients. J Clin Microbiol. 2005;43(4):197981.

6. Morooka K. [Convulsions and mild diarrhea]. Shonika (Tokyo). 1982;23:131-7.

7. Hall AJ, Rosenthal M, Gregoricus N, Greene SA, Ferguson J, Henao OL, et al. Incidence of acute gastroenteritis and role of norovirus, Georgia, USA, 2004-2005. Emerg Infect Dis. 2011;17(8):1381-8.

8. Okitsu-Negishi S, Okame M, Shimizu Y, Phan TG, Tomaru T, Kamijo S, et al. Detection of norovirus antigens from recombinant virus-like particles and stool samples by a commercial norovirus enzyme-linked immunosorbent assay kit. J Clin Microbiol. 2006;44(10):3784-6.

9. Rutjes SA, van den Berg HH, Lodder WJ, de Roda Husman AM Real-time detection of noroviruses in surface water by use of a broadly reactive nucleic acid sequence-based amplification assay. Appl Environ Microbiol. 2006;72(8):5349-58

10. Nishimura N, Nakayama H, Yoshizumi S, Miyoshi M, Tonoike $\mathrm{H}$ Shirasaki Y, et al. Detection of noroviruses in fecal specimens by direct RT-PCR without RNA purification. J Virol Methods. 2010;163(2):282-6.

11. Straub TM, Honer zu Bentrup K, Orosz-Coghlan P, Dohnalkova A, Mayer BK, Bartholomew RA, et al. In vitro cell culture infectivity 
assay for human noroviruses. Emerg Infect Dis. 2007;13(3):396403.

12. Guix S, Caballero S, Villena C, Bartolome R, Latorre C, Rabella N, et al. Molecular epidemiology of astrovirus infection in Barcelona, Spain. J Clin Microbiol. 2002;40(1):133-9.

13. Romani S, Mohebbi SR, Hosseini SM, Azimzadeh P, Vahedi M, Derakhshan F, et al. Prevalence of norovirus infection in children and adults with acute gastroenteritis, Tehran, Iran, 2008-2009. Food Environ Virol. 2012; p. 1-5

14. Fretz R, Herrmann L, Christen A, Svoboda P, Dubuis O, Viollier EH, et al. Frequency of Norovirus in stool samples from patients with gastrointestinal symptoms in Switzerland. Eur J Clin Microbiol In fect Dis. 2005;24(3):214-6.

15. Bucardo F, Nordgren J, Carlsson B, Paniagua M, Lindgren PE, Espinoza F, et al. Pediatric norovirus diarrhea in Nicaragua. J Clin Microbiol. 2008;46(8):2573-80.

16. Wu TC, Liu HH, Chen YJ, Tang RB, Hwang BT, Yuan HC. Comparison of clinical features of childhood norovirus and rotavirus gastroenteritis in Taiwan. J Chin Med Assoc. 2008;71(11):566-70.

17. Phan TG, Okame M, Nguyen TA, Maneekarn N, Nishio O, Okitsu S, et al. Human astrovirus, norovirus (GI, GII), and sapovirus infections in Pakistani children with diarrhea. J Med Virol.
2004;73(2):256-61.

18. Chhabra P, Chitambar SD. Norovirus genotype IIb associated acute gastroenteritis in India. J Clin Virol. 2008;42(4):429-32.

19. Colomba C, Saporito L, Giammanco GM, De Grazia S, Ramirez S, Arista S, et al. Norovirus and gastroenteritis in hospitalized children, Italy. Emerg Infect Dis. 2007;13(9):1389-91.

20. Nakagomi T, Correia JB, Nakagomi O, Montenegro FM, Cuevas LE, Cunliffe NA, et al. Norovirus infection among children with acute gastroenteritis in Recife, Brazil: disease severity is comparable to rotavirus gastroenteritis. Arch Virol. 2008;153(5):957-60.

21. Witlox KJ, Nguyen TN, Bruggink LD, Catton MG, Marshall JA. A comparative evaluation of the sensitivity of two automated and two manual nucleic acid extraction methods for the detection of norovirus by RT-PCR . JVirol Methods. 2008;150(1-2):70-2.

22. Schneider KR, Schneider RG, Hubbard M, Shukla R. Preventing foodborne illness: Norovirus. FSHN. 2005;518:1-3.

23. Hall AJ, Aron J. Updated norovirus outbreak management and disease prevention guidelines. US Department of Health and $\mathrm{Hu}$ man Services, Centers for Disease Control and Prevention. 2011.

24. Soares CC, Santos N, Beard RS, Albuquerque MC, Maranhao AG, Rocha LN, et al. Norovirus detection and genotyping for children with gastroenteritis, Brazil. Emerg Infect Dis. 2007;13(8):1244-6. 